\title{
Serum Zinc Alteration in full term Neonate with Hyperbilirubinemia before and after Phototherapy
}

\author{
S.A.Dabour ${ }^{1}$, E.H.Assar ${ }^{1}$,E.G.Behiry ${ }^{2}$ and D.A.Elsayed ${ }^{3}$ \\ ${ }^{1}$ Pediatrics Dept., Faculty of Medicine, Benha Univ., Benha, Egypt \\ ${ }^{2}$ Clinical pathology Dept., Faculty of Medicine, Benha Univ., Benha, Egypt \\ ${ }^{3}$ pediatrics Dept., Faculty of Medicine, Benha Univ., Benha, Egypt \\ E-Mail:Doaa1156@gmail.com
}

\begin{abstract}
Hyperbilirubinaemia is one of the commonest causes of admission to hospital in neonatal period. The final product of heme protein catabolism is an unconjugated bilirubin. One of the factors that affect the severity and incidence of jaundice is the level of serum zinc. This study aimed to evaluate serum zinc level in neonatal hyperbilirubinemia before and after phototherapyMethods:The study was conducted on two groups: Study group included 50 neonates hahyperbilirubinemia. Control group included 50 neonates. All groups were subjected to Full history, Full examination and Laboratory Investigations included:Serum zinc level before and (12-24hrs) after phototherapy. Total serum billirubin and direct.Results:patient group was significantly associated with higher TSB when compared to control group.Zinc level was significantly lower in cases when compared to control group. phototherapy in neonates with severe hyperbilirubinemia was associated with a significant increase in the serum zinc levels.all studied cases were stratified according to basal TSB level into moderate hyperbilirubinemia (TSB<18 mg/dL) and severe hyperbilirubinemia (TSB $\geq 18 \mathrm{mg} / \mathrm{dL}$ ). In both subgroups, zinc level increased significantly after phototherapy. Basal serum zinc level showed significant negative correlation with TSB. Receiver operating characteristic (ROC) curve of zinc level was conducted for discrimination between moderate and severe hyperbilirubinemia cases.Fair AUC was found (AUC $=0.760)$ at best cut of value of baseline zinc $(=84.5 \mathrm{ug} / \mathrm{dl})$, sensitivity was $82.4 \%$, specificity was $66.7 \%$, Conclusion:Phototherapy by reducing the bilirubin level causes an increase in the serum zinc level .
\end{abstract}

Keywords: Zinc-Neonate, Hyperbilirubinemia, Phototherapy.

\section{Introduction}

Hyperbilirubinaemia is one of the commonest causes of admission to hospital in the neonatal period amongst term babies in all settings [1].

Neonatal jaundice is associated with increased unconjugated bilirubin concentrations caused by the breakdown of red blood cells. Bilirubin can damage neurologic tissue and lead to bilirubin-induced neurologic dysfunction [2].

Bilirubin in itself is not completely detrimental and can exert a physiological protective effect due to its antioxidant properties [3].

Jaundice is the most common reason for admission during the 1st month of life. Multiple variables (maternal, infantile, during labor and environmental factors) affect the course and severity of jaundice. Although there may be a benefit to patients with mild hyperbilirubinemia, the subjects with high elevation of serum bilirubin are endangered due to accumulation of bilirubin in the brain tissue [4]

The final product of heme protein catabolism is an unconjugated bilirubin produced in the reticuloendothelial cells after a chain of enzymatic reactions by the oxygenase, reductase and nonenzymatic reducing agents. Conjugated bilirubin pigments can also be partly due to the deposition of the final product conjugations in hepatocyte by the enzyme bilirubin UDP-glucuronosyltransferase to form a polar water-soluble bilirubin glucuronide. One of the factors that affect the severity and incidence of jaundice is the level of serum zinc [3].

Physiopathology of idiopathic jaundice is unknown in the neonates. Animal studies show that oral administration of zinc decreases serum bilirubin level in the rats. [5]showed that zinc salts can deposit unconjugated bilirubin and that zinc sulfate suppressed enterohepatic circulation of bilirubin in hamsters.

Administration of zinc $(4 \mu \mathrm{mol} / \mathrm{kg})$ decreased carbon monoxide (CO) and bilirubin levels significantly one to six hours after treatment. Zinc salts and other elements such as strontium inhibit the hemoxygenase enzymes and as a result may prevent jaundice [3].

This study aimed to evaluate serum zinc level in neonatal hyperbilirubinemia before and after phototherapy.

\section{Subjects and methods}

\subsection{Subjects}

This prospective case/control study that was conducted on patients attending Pediatric Department Benha faculty of medicine. Approval of the study protocol by ethical scientific committee of benha university was obtained \& informed consent was obtained from the parents before enrollment in the study.

The present study was conducted on 50 neonates with hyperbilirubinemiaselected from Neonatal Intensive Care Unit In Benha Children Hospital \&Benha University Hospital, Their mean age was 4.5 days. They were 30 males and 20 females. In addition to 50 healthy neonates of matched age and gender.

New born who undergo exchange transfusion, had congenital anomalies, had inborn error of metabolism, sepsis and infection or whose mother had a history of diabetes were excluded from the study. Control group 
included 50 neonates, they was be healthy children, both sexes (male- Female), age (full term).

\section{All groups were subjected to the following:}

1) Full history

2) Full examination: to exclude any congenital anomalies or any manifestation of sepsis.

3) Investigations:

\section{Laboratory studies}

Sampling: three $\mathrm{ml}$ of venous blood was collected under aseptic precautions and divided tnto two tubes first for CBC and blood grouping and second for on glass plain tube,then centrifuged to separate serum immediately, during sample taking; the blood was allowed to be dropped slowly on the wall of the tube (to avoid hemolysis). The time between blood sampling and separation of the serum by centrifuge was about 2 hours.

Complete blood count.(CBC) was done for all samples using sysmex KX-21N (Sysmex Corporation, New York, USA) for hemoglobin level, hematocrit value, WBC count, and platelet count.

Total serum zinc levels were measured before and 12 - 24 hours after termination of phototherapy using the colorimetric method using 2-carboxy-2-hydroxy-5sulfoformazyl-benzene [Diagnostic and research reagents, Egypt]. And measured at WL: 610nm, linearity up to $1000 \mathrm{ug} / \mathrm{dl}$.

Assessment of levels of Total and direct bilirubin are competed automatically using a (Dialab autolayzer).

\subsection{Statistical analysis}

The collected data were tabulated and analyzed using SPSS version 16 software (SpssInc, Chicago, ILL Company). Categorical data were presented as absolute and relative (\%) frequencies. Chi-square test (X2), or Fisher's exact test (FET) were used to analyze categorical variables. Student " $t$ " test was used to analyze normally distributed variables among 2 independent groups. While non-parametric variables were analyzed using the Man Whitney U test. ROC curve was used to determine the cutoff value with optimum sensitivity and specificity. Regression analysis was run to detect the predictors. The accepted level of significance in this work was stated at $0.05(\mathrm{P}$ $<0.05$ was considered significant).

\section{Results}

The present study was conducted on 50 neonates with hyperbilirubinemia, with gestational age $37.80,7$ wks, their mean age was 4.51 .4 days and weight 3.1 $0.6 \mathrm{Kgs}$, they were 30 males and 20 females. In addition to 50healthy neonates of matched age, gender, gestational age and weight.

Most cases were delivered by CS (64\%), while 36\% were delivered by normal vaginal delivery ( NVD). Positive family history was found in 54\%. Cause of jaundice varied between studied cases; $44 \%$ had physiologic jaundice, $36 \%$ had incompatible ABO, $14 \%$ had incompatible $\mathrm{RH}$ and $6 \%$ had breast milk jaundice.Mean disease duration was 3.3 days. Table (1).

Phototherapy used was single in $20 \%$, double in $30 \%$, triple in $26 \%$ and intensive in $24 \%$. Patient group was significantly associated with higher TSB (17.4 $\pm 3.7)$, DSB (1.1 \pm 0.3$)$ when compared to control group. Otherwise, no significant differences were found in laboratory data between all studied cases and control groups.Management of hyperbilirubinemia was performed largely based on American academy of pediatrics (AAP) guidelines [6].

Zinc level was significantly lower in cases (80.9 $\pm 12.4 \mathrm{ug} / \mathrm{dl}$ ) when compared to control group (108.2 \pm $10.9 \mathrm{ug} / \mathrm{dl})$. Zinc level increased significantly after phototherapy $(173.8 \pm 49.4 \mathrm{ug} / \mathrm{dl})$ when compared to patients' basal levels as well as when compared to control group Fig (1).

All studied cases were stratified according to basal TSB level into moderate hyperbilirubinemia (TSB $<18$ $\mathrm{mg} / \mathrm{dL}$ ) and severehyperbilirubinemia (TSB $\geq 18$ $\mathrm{mg} / \mathrm{dL})$. In both subgroups, zinc level increased significantly after phototherapy $(\mathrm{p}<0.001$ for both). By calculating percentage change in zinc level after phototherapy in each group, revealed that in moderate hyperbilirubinemia, zinc increased by $33 \%$ from basal level, while in severe hyperbilirubinemia subgroup, zinc increased by $173.8 \%$ from basal level; and by comparing changes in both subgroups revealed that the change was higher in severe hyperbilirubinemia when compared to moderate hyperbilirubinemia subgroups (173.8\% versus $33.4 \%, \mathrm{p}<0.001)$ Table (2).

All studied cases were stratified according to phototherapy used. In all types of phothotherapy, zinc level increased significantly after phototherapy $(\mathrm{p}<0.001$ for each). By calculating percentage change in zinc level after phototherapy in each type of phototherapy, revealed that percentage change in zinc level increased with increased intensity of phototherapy; and by comparing these changes revealed that the change was higher in intense followed by triple, double and lastly single phototherapy $(44.7 \%, 100.3 \%, 145.8 \%$ and 204.7\%; $\mathrm{p}=0.001$ ) Table (2).

Basal serum zinc level showed significant negative correlation with TSB. Otherwise, no significant correlation was found between basal zinc levels with other studied parameters in hyperbilirubinemia neonates Table (3).

Receiver operating characteristic (ROC) curve of zinc level was conducted for discrimination between moderate and severe hyperbilirubinemia cases.Fair AUC was found (AUC $=0.760$ ) at best cut of value of baseline zinc $(=84.5 \mathrm{ug} / \mathrm{dl})$, sensitivity was $82.4 \%$, specificity was $66.7 \%$, PPV was $56 \%$, NPV was $88 \%$, accuracy was $72 \%$. Performance characteristics are shown in Fig (2)

Logistic regression analysis was conducted for prediction of hyperbilirubinemia, using age, gender, LBW Rh, zinc level as covariates. Low basal zinc level considered as predictor for hyperbilirubinemiain newborn infants. Table (4). 
Table (1) Clinical and laboratory investigations of all studied cases.

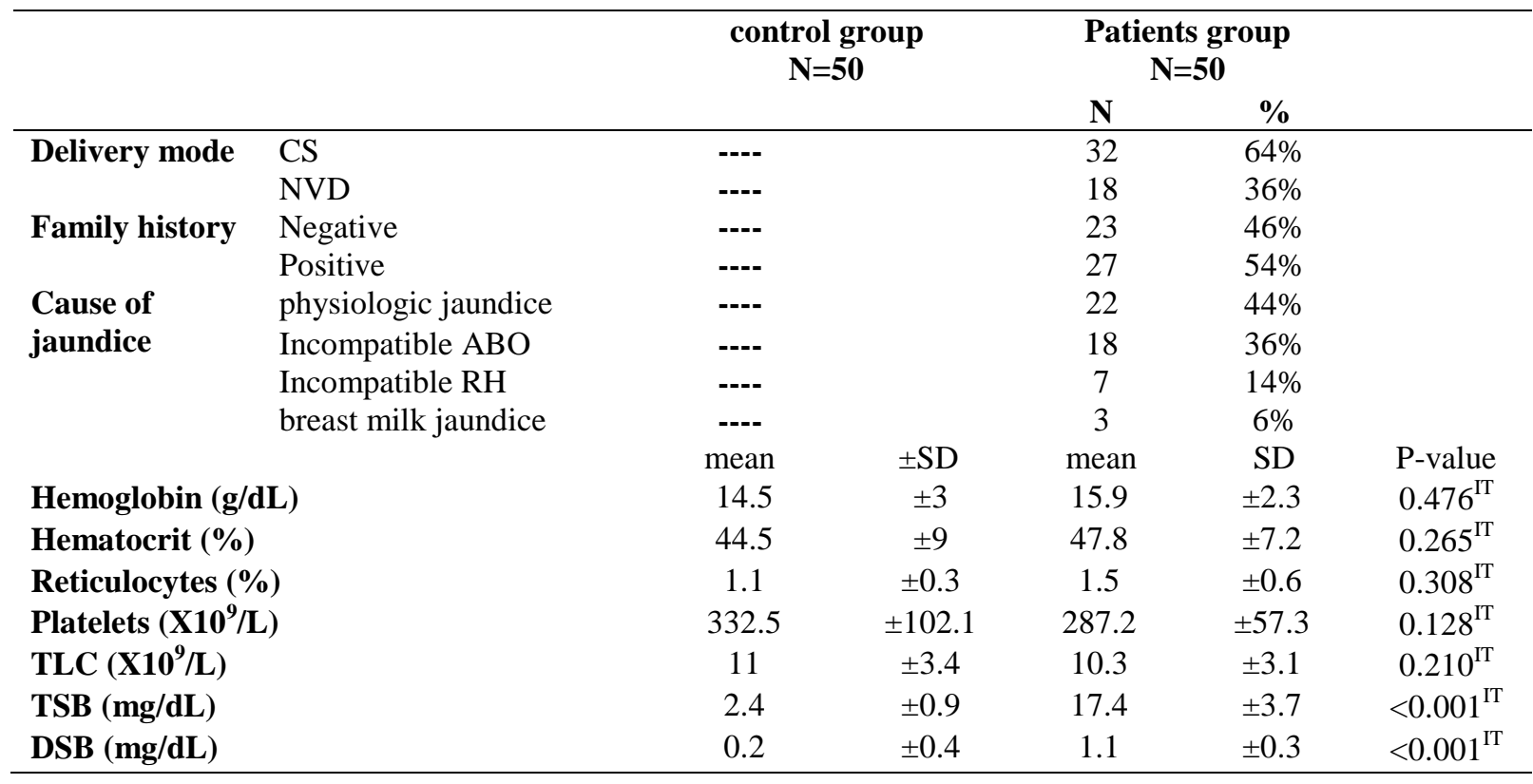

$\mathrm{SD}$, standard deviation; IT, independent t test; $\mathrm{C}$, Chi square test.

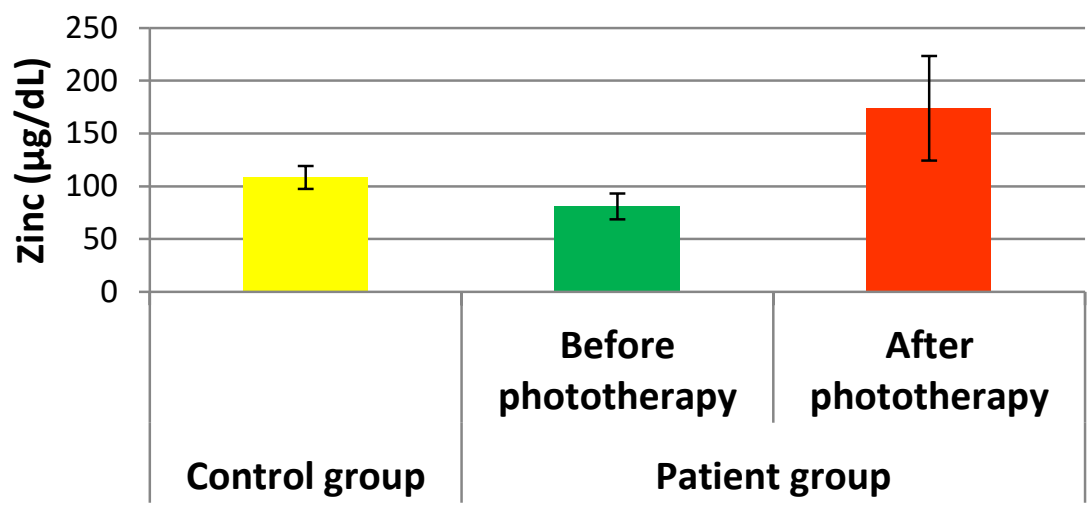

Fig (1) Zinc concentration in all studied groups, before and after phototherapy.

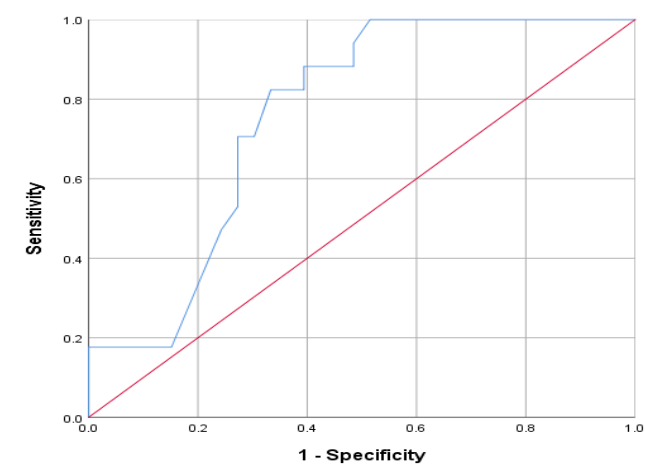

Fig (2) ROC curve of basal zinc levels for discrimination between moderate and severe hyperbilirubinemia cases. 
Table (2) Comparison of zinc concentration between moderate and severe hyperbilirubinemaia subgroups and according to phototherapy types in all studied cases.

\begin{tabular}{|c|c|c|c|c|c|c|c|c|c|}
\hline \multicolumn{10}{|c|}{$\begin{array}{l}\text { Comparison of zinc concentration between moderate and severe hyperbilirubinemaia subgroups } \\
\text { Patient group }\end{array}$} \\
\hline \multirow{6}{*}{$\begin{array}{l}\text { Moderate } \\
\text { hyperbilirubinemia }<18 \\
\text { Severe } \\
\text { hyperbilirubinemia } \geq 18\end{array}$} & \multicolumn{9}{|c|}{$\mathrm{N}=50$} \\
\hline & \multirow[b]{3}{*}{$\mathbf{N}$} & \multicolumn{4}{|c|}{ Zinc $(\mu \mathrm{g} / \mathrm{dL})$} & \multirow{3}{*}{$\mathbf{P}^{1}$} & \multirow{2}{*}{\multicolumn{2}{|c|}{$\begin{array}{c}\text { Percentage } \\
\text { change in zinc } \\
\text { level }(\%)\end{array}$}} & \multirow{3}{*}{$\mathbf{P}^{2}$} \\
\hline & & \multicolumn{2}{|c|}{$\begin{array}{c}\text { Before } \\
\text { phototherapy } \\
\mathbf{N}=17 \\
\end{array}$} & \multicolumn{2}{|c|}{$\begin{array}{c}\text { After } \\
\text { phototherapy } \\
\mathbf{N}=\mathbf{3 3} \\
\end{array}$} & & & & \\
\hline & & mean & \pm SD & mean & \pm SD & & mean & \pm SD & \\
\hline & 17 & 88.8 & 6.9 & 117.4 & 21.6 & $<0.001^{\mathrm{IT}}$ & 33.4 & 9.9 & \multirow{2}{*}{$<\underset{\mathrm{T}}{<0.001}$} \\
\hline & 33 & 76.9 & 12.7 & 202.9 & 51.1 & $<0.001^{\mathrm{IT}}$ & 173.8 & 25.4 & \\
\hline \multicolumn{10}{|c|}{ Comparison of zinc concentration according to phototherapy types in all studied cases } \\
\hline \multirow{4}{*}{ Phototherapy } & \multicolumn{9}{|c|}{$\begin{array}{l}\text { Patient group } \\
\quad \mathrm{N}=50\end{array}$} \\
\hline & \multicolumn{5}{|c|}{ Zinc $(\boldsymbol{\mu g} / \mathrm{dL})$} & \multirow{2}{*}{\multicolumn{3}{|c|}{$\begin{array}{l}\text { Percentage } \\
\text { change in } \\
\text { zinc level }\end{array}$}} & \multirow{3}{*}{$\mathrm{P}^{2}$} \\
\hline & \multirow[b]{2}{*}{$\mathbf{N}$} & \multicolumn{2}{|c|}{$\begin{array}{c}\text { Before } \\
\text { phototherapy } \\
\mathrm{N}=17 \\
\end{array}$} & \multicolumn{2}{|c|}{$\begin{array}{c}\text { After } \\
\text { phototherapy } \\
\mathrm{N}=\mathbf{3 3}\end{array}$} & & & & \\
\hline & & mean & $\begin{array}{c} \pm \mathrm{S} \\
\mathrm{D}\end{array}$ & mean & \pm SD & & mean & $\begin{array}{c} \pm \mathrm{S} \\
\mathrm{D}\end{array}$ & \\
\hline single & 10 & 87.7 & 6.8 & 125.1 & 36.4 & $<0.001^{\mathrm{PT}}$ & 44.7 & $\begin{array}{c}12 . \\
2\end{array}$ & \multirow{4}{*}{$0.001^{\mathrm{A}}$} \\
\hline double & 15 & 82.5 & $\begin{array}{c}10 . \\
9\end{array}$ & 158.5 & 51.9 & $<0.001^{\mathrm{PT}}$ & 100.3 & 32. & \\
\hline triple & 13 & 82.7 & $\begin{array}{c}12 . \\
0\end{array}$ & 196.2 & 55.6 & $<0.001^{\mathrm{PT}}$ & 145.8 & $\begin{array}{c}31 . \\
4\end{array}$ & \\
\hline Intensive & 12 & 71.5 & $\begin{array}{c}13 . \\
8\end{array}$ & 209.3 & 58.3 & $<0.001^{\mathrm{PT}}$ & 204.7 & $\begin{array}{c}38 . \\
4\end{array}$ & \\
\hline
\end{tabular}

SD, standard deviation; PT, paired sample T test.A, ANOVA; P1, comparison between before and after phototherapy in each subgroup; p2, comparison between change in zinc level according to phototherapy types.

Table (3) Correlation of basal zinc levels with other parameters in all studied cases.

\begin{tabular}{lcc}
\hline & & Basal Zinc \\
\hline Age & $\mathrm{r}$ & $\mathrm{p}$ \\
Gestational age & $0.135-$ & 0.352 \\
Weight & 0.11 & 0.446 \\
SBP & $0.218-$ & 0.128 \\
DBP & 0.104 & 0.471 \\
Temperature & $0.014-$ & 0.921 \\
RR & $0.192-$ & 0.182 \\
HR & $0.105-$ & 0.469 \\
Hemoglobin & 0.113 & 0.434 \\
Hematocrit & 0.046 & 0.749 \\
Reticulocytes & 0.207 & 0.148 \\
Platelets & $0.018-$ & 0.900 \\
TLC & $0.053-$ & 0.717 \\
TSB & $0.195-$ & 0.176 \\
DSB & $0.495-$ & $<0.001$ \\
Duration & $0.145-$ & 0.315 \\
\hline
\end{tabular}

r, Pearson's correlation coefficient. 
Table (4) Regression analysis for prediction of neonatal hyperbilirubinemaia.

\begin{tabular}{lcccc}
\hline & p & OR & \multicolumn{2}{c}{ 95\% CI } \\
\hline Age & 0.125 & 0.932 & 0.851 & 1.020 \\
Gender & 0.749 & 0.922 & 0.562 & 1.515 \\
LBW $(<2.5$ Kg) & 0.583 & 0.842 & 0.455 & 1.557 \\
Positive neonatal Rh and negative maternal Rh & 0.583 & 1.188 & 0.642 & 2.197 \\
Basal zinc & $<0.001$ & 0.736 & 0.642 & 0.844 \\
\hline
\end{tabular}

\section{Discussion}

Zinc deficiency in pregnant women causes numerous complications for the fetus during pregnancy, such as structural malformations, intrauterine growth retardation (IUGR), premature birth, and SGA in different animal species and human. It is estimated that approximately $50 \%$ of women of childbearing age suffer from zinc deficiency. Studies found a relationship among low maternal serum zinc levels, low transferred zinc to the fetus and increase risk of developmental defects. Zinc plays both the structural and enzymatic roles in many proteins. A part of teratogenic effects of zinc deficiency can be due to the changes in the activity of proteins in the embryo ${ }^{[7]}$.

In our study Zinc level was significantly lower in cases when compared to control group.

This agrees with ${ }^{[3]}$ who demonstrated that the serum zinc level of the neonates with jaundice was lower than that of the ones without jaundice.

In our study Zinc level increased significantly after phototherapy when compared to patients' basal levels as well as when compared to control group.

Zinc is one of the essential elements in neonatal growth, protein synthesis and regulation of inhibitory and stimulatory synapses of the brain. Zinc lower the bilirubin levels by inhibition of the normal enterohepatic cycling of unconjugated bilirubin (UCB) [8].The mechanism could underlie the observed relation between zinc and bilirubin levels investigated previously as in vitro studies

M.Sobieszczanska et al., [9] showing that zinc salts can precipitate unconjugated bilirubin at physiological $\mathrm{pH}$, because the chemical structure of bilirubin has the potential to chelate with metal ions, such as zinc.

In vivo studies showed that zinc salts can inhibit the enterohepatic circulation of unconjugated bilirubin by precipitating it in the intestine because prescription of zinc salts causes a decrease in serum unconjugated bilirubin but an increase in the fecal bilirubin excretion [5].

In this study phototherapy in neonates with severe hyperbilirubinemia was associated with a significant increase in the serum zinc levels.

Recently some studies have proposed using zinc salts for lowering bilirubin levels in neonates with jaundice or preventing the incidence of neonatal jaundice [10].

The results of these studies should be considered when evaluating the effect of zinc therapy in hyperbilirubinemic neonates. ${ }^{[11]}$ found that the incidence of hyperbilirubinemia and requirement of phototherapy did not differ with zinc supplementation, except for a shorter duration of phototherapy. None of these studies reported any zinc toxicity in zinc supplemented neonates (the studies included all neonates, not only neonates with hyperbilirubinemia). As serum zinc level is higher in hyperbilirubinemic neonates ${ }^{[12]}$, zinc supplementation in addition to phototherapy may cause an increase in the serum zinc level and zinc toxicity.

This study showed that, all studied cases were stratified according to basal TSB level into moderate hyperbilirubinemiaand severe hyperbilirubinemia. In both subgroups, zinc level increased significantly after phototherapy $\quad(p<0.001$ for both). By calculating percentage change in zinc level after phototherapy in each group, revealed that in moderate hyperbilirubinemia, zinc increased by $33 \%$ from basal level, while in severe hyperbilirubinemia subgroup, zinc increased by $173.8 \%$ from basal level; and by comparing changes in both subgroups revealed that the change was higher in severe hyperbilirubinemia when compared to moderate hyperbilirubinemia subgroups $(173.8 \%$ versus $33.4 \%, p<0.001)$.

This agrees with ${ }^{[13]}$ who found that, there were significant adverse correlations between the serum bilirubin and zinc levels before phototherapy and after phototherapy. There was a significant increase in the zinc levels after phototherapy in these neonates. There was a significant increase in the percentage of neonates with zinc levels > $200 \mathrm{mg} / \mathrm{dL}$ after phototherapy (before phototherapy 3 (4\%) neonates, after phototherapy $10(15 \%)$ neonates.

This agrees with ${ }^{[14]}$ who found that, Phototherapy was associated with a significant increase in the serum zinc level in neonates with severe hyperbilirubinemia (TSB $>18 \mathrm{mg} / \mathrm{dL}$ ) but not in those with mild moderate hyperbilirubinemia $(\mathrm{TSB}<18 \mathrm{mg} / \mathrm{dL}$ ). In addition, phototherapy caused a significant increase in the rate of zinc with potentially toxic levels (zinc > 200) in only neonates with severe hyperbilirubinemia.

This study showed that no significant correlation was found between basal zinc levels and DSB.

This agrees with ${ }^{[3]}$ who demonstrated that there was no relationship between serum level of direct bilirubin and zinc.

This study showed that, basal serum zinc level showed significant negative correlation with TSB.

The mechanism could underlie the observed relation between zinc and bilirubin levels investigated previously as in vitro studies showing that zinc salts that precipitate unconjugated bilirubin at physiological 
$\mathrm{pH}$, because the chemical structure of bilirubin has the potential to chelate with metal ions, such as zinc. This agrees withprevious findings ${ }^{[\mathbf{1 5}]}$ that showed an inverse relationship between the levels of unconjugated bilirubin and serum zinc.

\section{Conclusion}

Phototherapy by reducing the bilirubin level causes an increase in the serum zinc level. Accordingly, it appears that using soluble zinc salts that can be absorbed into the blood system is not safe in hyperbilirubinemic neonates.

\section{References}

[1] M.K.Mwaniki, H.W.Gatakaa, F.N.Mturi, C.R.Chesaro, J.M.Chuma, N.M.Peshu, L.Mason, P.Kager, K.Marsh, M.English, J.A.Berkley,An increase in the burden of neonatal admissions to a rural district hospital in Kenya over 19 years. BMC Public Health, Vol.10(1), PP.591-599, 2010.

[2] S.Gazzin,C.Tiribelli,Bilirubin-induced neurological damage. The J.,Maternal-Fetal \& Neonatal Medicine, Vol.24(1), PP.154-5,2011.

[3] H.Boskabadi, F.Ashrafzadeh, F.Azarkish, A.Khakshour, Complications of Neonatal Jaundice and the Predisposing Factors in Newborns. J.,BABOL University of Medical Sciences, Vol.17 (9), pp.7-13, 2015.

[4] H.Boskabadi, G.Maamouri, S.Mafinejad, F.Rezagholizadeh ,Clinical course and prognosis of hemolytic jaundice in neonates in North East of Iran. Macedonian J.,Medical Sciences, Vol.4(4), pp.403-7,2011.

[5] N.Méndez-Sánchez, M.Martínez, V.González, E.Roldán-Valadez, M.A. Flores, M.Uribe,Zinc sulfate inhibits the enterohepatic cycling of unconjugated bilirubin in subjects with Gilbert's syndrome. Annals of hepatology, Vol.1(1), pp.403,2002.

[6] H.C.Chou,C.T.Chien, P.N.Tsao, W.S.Hsieh, C.Y.Chen, M.H. Chang, Prediction of severe neonatal hyperbilirubinemia using cord blood hydrogen peroxide: a prospective study. PloS one, Vol.9(1), PP.251-259,2014.

[7] L.A.Hanna, M.S.Clegg, R.G.Ellis-Hutchings, B.J.Niles, C.L.Keen,The influence of gestational zinc deficiency on the fetal insulin-like growth factor axis in the rat. Experimental Biology and Medicine, Vol.235(2), PP.206-14,2010.

[8] L.Vitek, L.Muchová, J.Zelenka, M.Zadinová, J.Malina,The effect of zinc salts on serum bilirubin levels in hyperbilirubinemic rats. J.,pediatric gastroenterology and nutrition, Vol.40(2), PP.135-40,2005.

[9] M.Sobieszczanska, S.Tubek, R.Szygula, A.Bunio,Is the zinc neuroprotective effect caused by prevention of intracellular zinc accumulation. AdvClinExp Med, Vol. 21(2), pp.245-8,2012.

[10] A.Mohammadzadeh, A.S.Farhat, R.Iranpour,Effect of clofibrate in jaundiced term newborns. The Indian J.,Pediatrics; Vol. 72(2), PP.123,2005.

[11] A.Kumar, N.K.Bagri, S.Basu, R.K.Asthana,Zinc supplementation for neonatal hyperbilirubinemia: a randomized controlled trial. Indian pediatrics, Vol.51(5), PP.375-8,2014.

[12] T.Huseyin, K.Cahit, A.Fatih, A.Recep, Handan ALPSerum concentration of zinc, magnesium, manganese and copper in neonatal jaundice. Ataturk Unive Tip Dergisi, Vol.32(1), PP.912,2000 .

[13] Z.Mosayebi, M.Rahmani, S.B.Ardakani, M.Sheikh, M.Shariat, G. Rezaeizadeh,Evaluation of serum zinc levels in hyperbilirubinemic neonates before and after phototherapy. Iranian J.,pediatrics; Vol. 26(3), PP.24-35,2016.

[14] S.Saravanan, A.S.Raghuram,Incidence of Zinc Toxicity as a Complication of Phototherapy , Vol.42(2), PP.92-99,2010.

[15] A.J.Piazza, B.J.Stoll, R.M.Kliegman, R.E.Behrman, H.B.Jenson, B.F. Stanton, Nelson textbook of pediatrics. , Vol.4, PP.192-199,2010. 